\title{
Probabilistic Thermal and Electromagnetic Analyses of Subsea Solenoid Valves for Subsea Blowout Preventers
}

\author{
Baoping Cai - Yonghong Liu* - Congkun Ren - Aibaibu Abulimiti - Xiaojie Tian - Yanzhen Zhang \\ College of Mechanical and Electronic Engineering, China University of Petroleum, China
}

\begin{abstract}
A prototype of subsea solenoid valve for subsea blowout preventers is designed and manufactured. The deterministic and probabilistic thermal and electromagnetic finite element analyses are performed by using ANSYS software. The effects of uncertainties of five material properties, four physical dimensions and an applied voltage on the maximum temperature within the valve and the electromagnetic force with a given air gap are researched by means of Monte Carlo simulation (MCS) and response surface method (RSM). The thermal and electromagnetic experiments were done to validate the finite element analysis results. The results show that the radius of magnetic ring, applied voltage and thermal conductivity of $440 \mathrm{C}$ stainless steel have significant effects on the maximum temperature of subsea solenoid valve. The radius of plunger and inside radius of plunger sleeve have significant effects on the electromagnetic force of subsea solenoid valve. The results of finite element analysis and thermal and electromagnetic experiments indicate good matches. Therefore, the probabilistic finite element analysis shows its advantages in improving the development process and performance of subsea solenoid valves.
\end{abstract}

Keywords: finite element methods, electromagnetic forces, electromagnetic heating, probability, valves, subsea solenoid valve

\section{O INTRODUCTION}

Subsea blowout preventers (BOP) play an extremely important role in providing safe working conditions for drilling activities in $3000 \mathrm{~m}$ ultra-deep water regions. Two redundant multiplex control pods, normally located on the lower marine riser package on the seafloor, are of crucial importance for the performance and reliability of BOP systems. The control pods contain 224 subsea solenoid valves immersed in low-temperature and high-pressure seawater [1]. As compared to shear seal valves, this valve provides about $70 \%$ savings in space reduction, which reduces the size and weight of subsea control systems greatly. Therefore, to maximize the electromagnetic force for a specific small volume valve, the main limiting quantity of maximum allowed temperature in seawater has to be considered [2].

The thermal and electromagnetic analyses for various electromagnetic devices have been performed by using the Finite Element Analysis (FEA) method. Tao et al. [3] developed an optimal design method for a high-speed response solenoid valve to achieve larger magnetic force and low power by using the FEA method. Moses et al. [4] studied the performance of a conventional electromagnetic actuator and a non-conventional electromagnetic device in order to demonstrate the advantages of the FEA technique in speeding up the design process and improving the performance of final products. Yatchev et al. [5] proposed a methodology to optimize a permanent magnet linear actuator with soft magnetic mover for electromagnetic valve. The flux density distribution, electromagnetic force and steady state temperature distribution were researched by finite element analysis in order to verify the obtained optimal solution. Yang and Huang [6] designed a novel electromagnetic actuator which can produce three-dimensional forces for miniature magnetically levitated rotating machines via the FEA software. Angadi et al. [7] constructed a comprehensive multi-physics finite element model of a solenoid valve used in an automobile transmission to make predictions of the stresses, strains and temperatures within the solenoid valve. The results predict that the valve is susceptible to a coupled electrical-thermo-mechanical failure mechanism. Wu et al. [8] presented a design methodology of a normal stress electromagnetic linear actuator for fast tool servos during non-rotationally symmetric diamond turning based on analytical and finite element methods magnetic circuit analysis. The magnetic flux density and magnetic strength intensity of magnetorheological valve were also researched by using the FEA method [9] and [10]. Lipus et al. [24] presented model devices for magnetic water treatment, optimized for scale control at water capacities up to a few $\mathrm{m}^{3} / \mathrm{h}$, using the computational program OPERA 15R1 with the FEA method.

From these literatures, it can be seen that the FEA method has been widely used to study electromagnetic devices. However, these analyses are mainly deterministic. The reliability issues of electromagnetic devices have not been investigated using the FEA method. To address the growing need for stochastic and probabilistic finite element analysis, ANSYS Inc. released the ANSYS Probabilistic Design System (PDS). The PDS is an analysis technique for assessing the effect of uncertain input parameters 
and assumptions on the model. This can account for the randomness in input variables such as material properties, boundary conditions, loads and geometry [11] and [12]. The PDS includes both the Monte Carlo Simulation (MCS) method as well as Response Surface Method (RSM).

The PDS have been used to study the probabilistic problems for various structures. Nakamura and Fujii [13] demonstrated the probabilistic thermal analysis of an atmospheric re-entry vehicle structure and investigated the probabilistic temperature response by using MCS. Zulkifli et al. [14] evaluated the reliability or fatigue life of the solder joints in the ball grid array package by using RSM. Nemeth et al. [15] studied the effect of specimen dimension of single crystal $\mathrm{SiC}$ on the strength response by using PDS. Liu and Zheng [16] studied the strength reliability of composite laminated high pressure hydrogen storage vessel by using MCS and RSM. Cai et al. [17] and [18] investigated the buckling behaviours of filamentwound carbon fibre-epoxy composite pressure vessel with aluminium liner and composite long cylinders by using PDS.

This work aims at studying the effects of uncertainties of material properties, physical dimensions and applied voltage on the thermal and electromagnetic issues by using the probabilistic FEA method. Five material properties, four physical dimensions and an applied voltage are taken as random input parameters, and the maximum temperature within the valve and the electromagnetic force with a given air gap are taken as random output responses. The thermal and electromagnetic experiments were performed to validate the finite element analysis results.

\section{FINITE ELEMENT ANALYSIS}

\subsection{Subsea Solenoid Valve}

The subsea solenoid valve is designed as a solenoid operated switching spring return actuator, which is mainly composed of a cover, a spring, a spring pocket, a coil, a coil bobbin, a plunger, a plunger sleeve, and a magnetic ring, as shown in Fig. 1. The plungertype structure is intended to produce small size [19] and [20]. When the coil is energized by DC voltage, the plunger of the valve retracts upward and extends downwards by releasing the stored energy from the spring.

The cover of the actuator is made of AISI $316 \mathrm{~L}$ austenitic stainless steel due to its high corrosion resistance to seawater, high strength, and high durability [21]. However, AISI 316L stainless steel is non-magnetic. Therefore, four components including plunger, spring pocket, plunger sleeve, and magnetic ring are used to form a magnetic circuit. They are made of AISI $440 \mathrm{C}$ martensitic stainless steel, which is strongly magnetic but has lower corrosion resistance to seawater than AISI 316L austenitic stainless steel [22]. All of the gaps within the valve, for example, the gap between the coil and the magnetic ring, are filled with conduction oil in order to transfer heat power and prevent high-pressure seawater from crushing the actuator. The coil conducts the current that provides magnetic flux, and it consists of numerous turns and layers of conducting copper wire, insulation and bonding material. The hydraulic fluid used in the subsea solenoid valve is water-glycol solutions, but not oil in order to reduce the pollution to ocean [23].

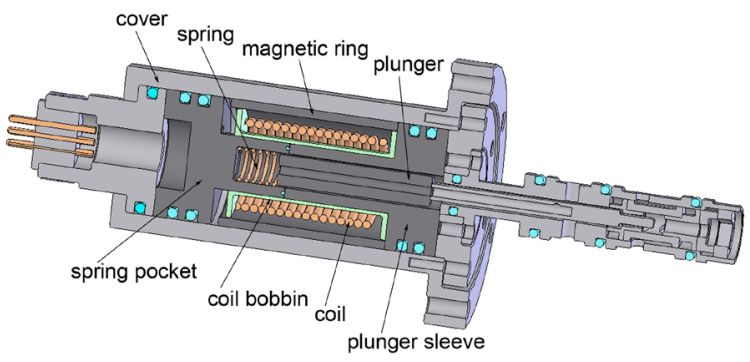

a)

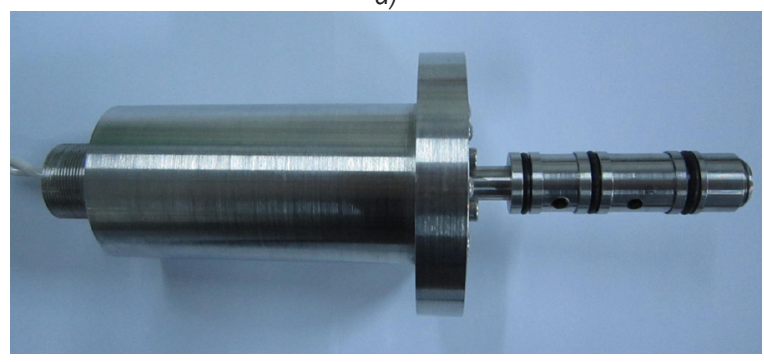

b)

Fig. 1. a) schematic diagrams, and b) prototype of the subsea solenoid valve

\subsection{Deterministic Analysis}

A thermal and electromagnetic model of the solenoid valve is developed in the finite element package ANSYS as shown in Fig. 2. Six materials including 316L stainless steel, 440C stainless steel, copper, Nylon, conduction oil and water-glycol solution are defined in the model.

For the thermal analysis, the valve is described using 2-D thermal solid element PLANE55. The element is defined by four nodes with a single degree of freedom at each node. It can be used as a plane element or as an axisymmetric ring element with 
a 2-D thermal conduction capability. The model is meshed free, and the number of nodes and elements are 1670 and 3189, respectively. Free convection is assumed on the outer boundaries of the valve, expect on the line of symmetry, where axisymmetric boundary condition is assumed. Finally, the thermal analysis of the solenoid valve is performed to obtain the temperature distribution.

For the electromagnetic analysis, 2-D coupledfield solid element PLANE 13 is used to describe the valve. The element is defined by four nodes with up to four degrees of freedom per node. It has a non-linear magnetic capability for modelling B-H curves or permanent magnet demagnetization curves. Similarly, the model is meshed free, and the number of nodes and elements are 1671 and 3182, respectively. The magnetic force boundary conditions are applied on the component of plunger, the uniform current density is applied on the elements of coil, and the flux parallel line conditions are applied on the all the outer boundaries. Finally, the magnetic flux line, magnetic flux density and electromagnetic force are predicted by performing the electromagnetic analysis.

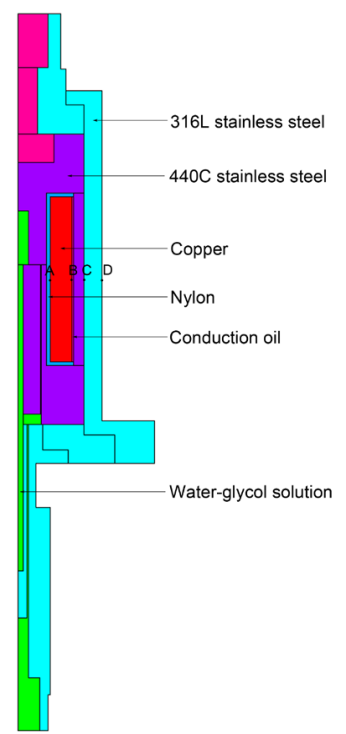

Fig. 2. Finite element model of the subsea solenoid valve

\subsection{Probabilistic Analysis}

The probabilistic finite element thermal and electromagnetic analyses of the subsea solenoid valve are performed by mean of ANSYS/PDS. The PDS is based on the ANSYS parametric design language, which allows users to parametrically build a finite element model, solve it, obtain results and extract characteristic results parameters such as the maximum temperature and maximum electromagnetic force for example. The PDS includes MCS and RSM. The MCS does not make any simplification or assumptions in the deterministic of probabilistic model, and the required number of simulations is not a function of the number of input variables, whereas this method requires plenty of computational time. The RSM replaces the true input-output relationship of MCS by an approximation function, and the evaluation of the response surface is much faster than a finite element solution. However, this method is unusable when true input-output relationship is not continuous [9].

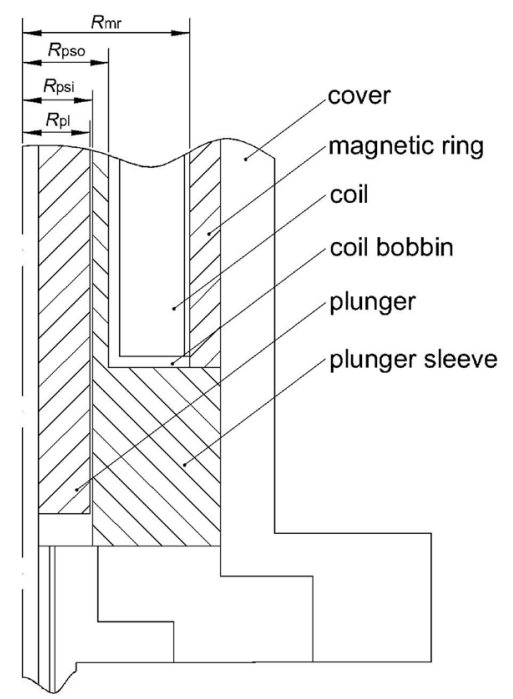

Fig. 3. Physical dimensions of the subsea solenoid valve

In this work, both of MCS and RSM are used to execute the probabilistic finite element thermal and electromagnetic analyses of the subsea solenoid valve. For the thermal analysis, the material properties including thermal conductivity of $316 \mathrm{~L}$ stainless steel, 440C stainless steel and conduction oil, and convection heat transfer coefficient of seawater, physical dimensions including the radius of the plunger, inside and outside radiuses of plunger sleeve, and the radius of magnetic ring as shown in Fig. 3 , and applied voltage are taken as random input parameters, and the maximum temperature within the valve is taken as random output response. For the electromagnetic analysis, the material properties including relative permeability of $440 \mathrm{C}$ stainless steel, physical dimensions as shown in Fig. 3 and applied voltage are taken as random input parameters, and the maximum electromagnetic force is taken as random output response. The statistical characteristics of material properties, physical dimensions and applied voltage are given in Table 1. The standard deviations 
Table 1. Statistical characteristic of material properties and dimensions

\begin{tabular}{llcccc}
\hline Property & Description & Unit & Mean & COV & Distribution \\
\hline$k_{316}$ & Thermal conductivity of 316L stainless steel & $\mathrm{W} /(\mathrm{mK})$ & 15 & 0.06 & Gauss \\
\hline$k_{440}$ & Thermal conductivity of 440C stainless steel & $\mathrm{W} /(\mathrm{mK})$ & 24.2 & 0.06 & Gauss \\
\hline$k_{\text {oil }}$ & Thermal conductivity of conduction oil & $\mathrm{W} /(\mathrm{mK})$ & 0.111 & 0.02 & Gauss \\
\hline$h_{\text {sea }}$ & Convection heat transfer coefficient of seawater & $\mathrm{W} /(\mathrm{mK} 2)$ & 200 & 0.01 & Gauss \\
\hline$\mu_{440}$ & Relative permeability of 440C stainless steel & - & 10000 & 0.05 & Gauss \\
\hline$R_{\mathrm{pl}}$ & Radius of plunger (see Fig. 2) & $\mathrm{m}$ & 0.0063 & 0.004 & Gauss \\
\hline$R_{\mathrm{psi}}$ & Inside radius of plunger sleeve (see Fig. 2) & $\mathrm{m}$ & 0.0065 & 0.003 & Gauss \\
\hline$R_{\mathrm{ps} 0}$ & Outside radius of plunger sleeve (see Fig. 2) & $\mathrm{m}$ & 0.0080 & 0.003 & Gauss \\
\hline$R_{\mathrm{mr}}$ & Radius of magnetic ring (see Fig. 2) & $\mathrm{m}$ & 0.0155 & 0.002 & Gauss \\
\hline$U$ & Applied voltage & $\mathrm{V}$ & 16 & 0.010 & Gauss \\
\hline
\end{tabular}

of variables are expressed as the product of mean valves and Coefficient of Variations (COV).

For both of the probabilistic thermal and electromagnetic analyses, the Latin Hypercube Sampling was selected for MCS due to the fact that this technique avoids repeating samples that have been evaluated, and also forces the tails of a distribution to participate in the sampling process. The central composite design was used to locate the sampling points in the design space for RSM.

\section{EXPERIMENTS}

In order to verify the finite element analysis results, the temperature within the subsea solenoid valve and electromagnetic force as a function of air gap were measured. Four resistance thermometer sensors (ZYWRNK-191, ZhongYiHuaShi, China) were fixed in Point A, B, C and D when the coil was wound and the valve was installed, as shown in Fig. 2. The steady state temperatures in the four points were measured when the solenoid was energized by applied DC voltage of $16 \mathrm{~V}$ in the constant temperature bath of $10{ }^{\circ} \mathrm{C}$.

A static experiment was performed to measure the relationship between the electromagnetic force and the air gap. The applied DC power was also supplied by a switching power supply (RXN-3020D), which is set to $16 \mathrm{~V}$. The displacement of the plunger was determined by an eddy current displacement sensor (JX70-04-B-M16*1-75-03K), and the force was measure by an S-shape force sensor (PST-20). By recoding the voltage outputs of the force sensor and eddy current sensor, the relationship between the magnetic force and the air gap could be calculated. a)

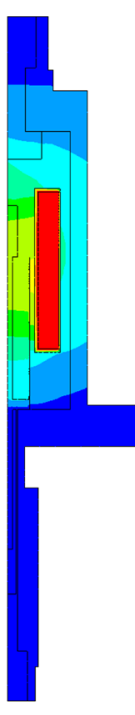

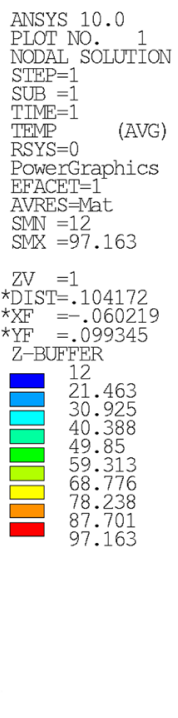
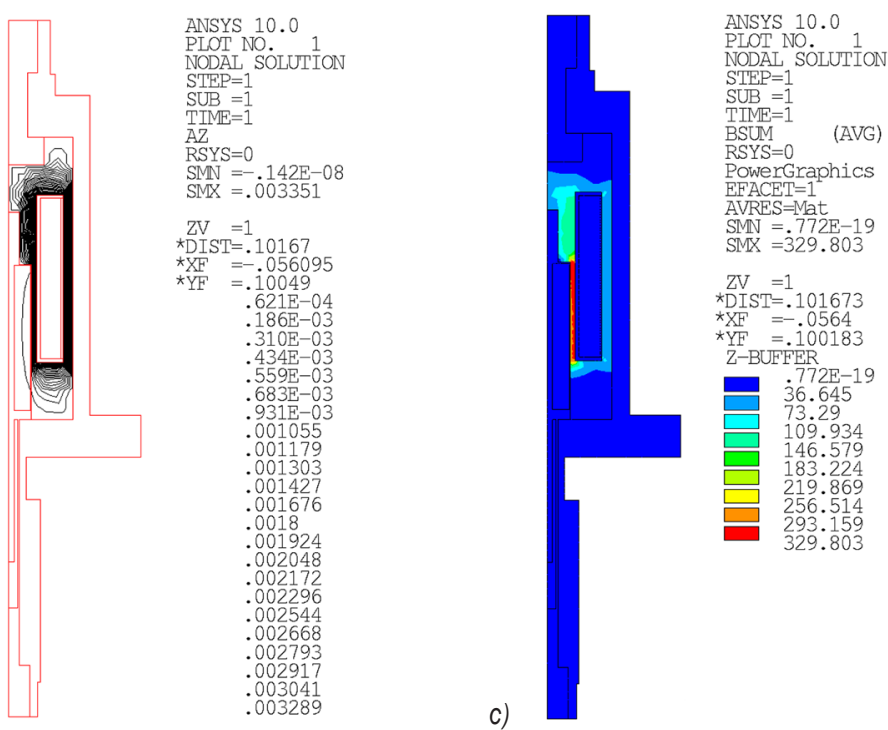

Fig. 4. Distributions of a) temperature, b) magnetic flux line, and c) magnetic flux density 


\section{RESULTS AND DISCUSSION}

\subsection{Comparison of Analysis and Experimental Results}

The distributions of temperature, magnetic flux line and magnetic flux density predicted by using deterministic finite element analysis are shown in Fig. 4. As expected, the maximum temperature of $97.16^{\circ} \mathrm{C}$ is found within the center of the coil, which is lower than the maximum allowed temperature of $120^{\circ} \mathrm{C}$. The minimum temperatures are located near the ends of the valve, which are for from the coil as shown in Fig. 4a. From Figs. 4b and c it can be seen that the main flux line is around the excited coil with a certain leakage.

The predicted and experimental temperatures in Point A, B, C and D (see Fig. 2) are plotted as shown in Fig. 5. It can be seen that they have a similar trend except that the predicted temperatures are a littler higher than the experimental temperatures. The results verify that the ANSYS-based temperature calculation is correct.

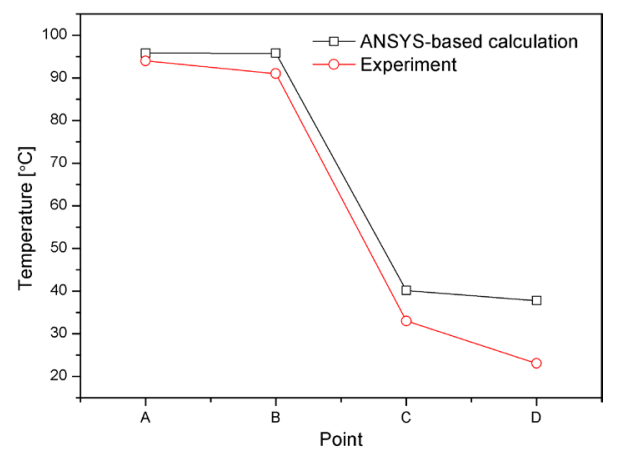

Fig. 5. Predicted and experimental temperature of the subsea solenoid valve

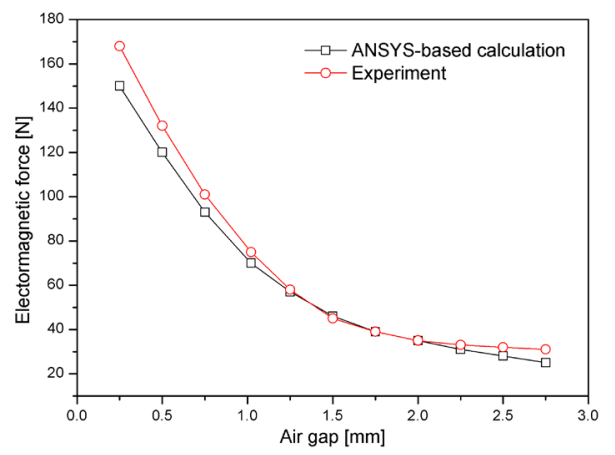

Fig. 6. Predicted and experimental electromagnetic force of the subsea solenoid valve

The predicted and experimental electromagnetic force as a function of air gap is plotted as shown in Fig. 6. With the increase of air gap, the electromagnetic force decreases rapidly. The experimental and predicted electromagnetic forces show a good agreement except that the experimental one is slightly higher than the predicted one. The results verify that the ANSYS-based electromagnetic force calculation is correct.

\subsection{Probabilistic Thermal Analysis Results}

The distribution function histograms of maximum temperature obtained by means of MCS and RSM are shown in Fig. 7. It can be seen that for MCS, the sampling range of maximum temperature is between 84.97 and $104.42{ }^{\circ} \mathrm{C}$, and the mean value and standard deviation are 95.90 and $2.94{ }^{\circ} \mathrm{C}$, respectively. For RSM, the sampling range is between 83.89 and $104.97{ }^{\circ} \mathrm{C}$. The mean value and standard deviation are 95.89 and $2.92{ }^{\circ} \mathrm{C}$, respectively. The sampling range of the maximum temperature for RSM is bigger than that for MCS slightly due to that fact that RSM ran more Monte Carlo simulations. The mean maximum temperature for MCS and RSM are a little lower than the deterministic analysis results of $97.16{ }^{\circ} \mathrm{C}$, whereas the error is very small.
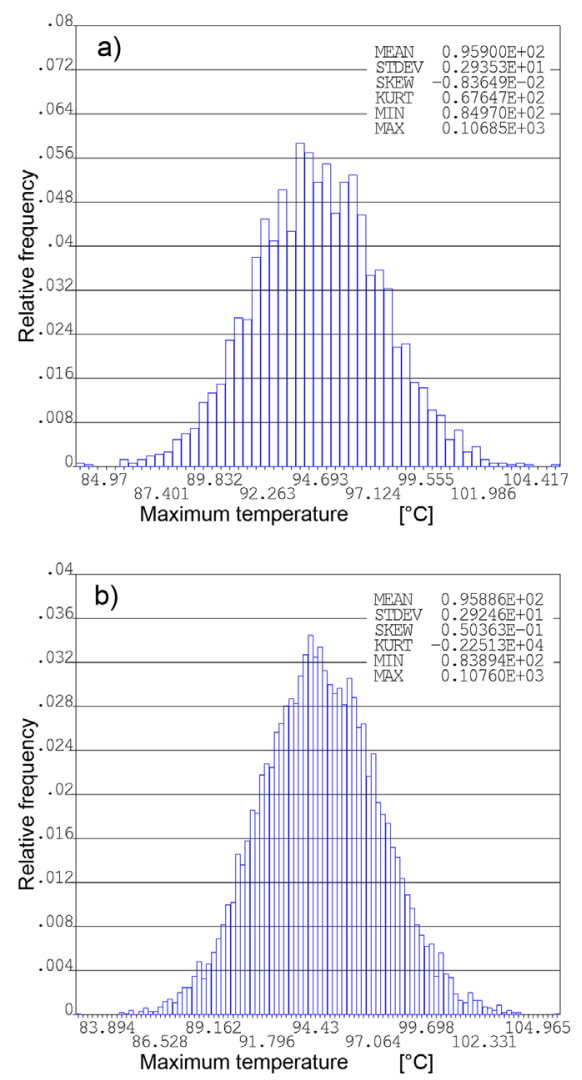

Fig.7. Distribution function histogram of maximum temperature; a) MCS, and b) RSM 
Cumulative distribution function of maximum temperature with $95 \%$ confidence limit is shown in Fig. 8. The value of the cumulative distribution function at each point states the probability that the related parameter lays under the point. Therefore, when maximum temperature is $96{ }^{\circ} \mathrm{C}$, the MCS and RSM almost have the same probability of failure of around $37 \%$.
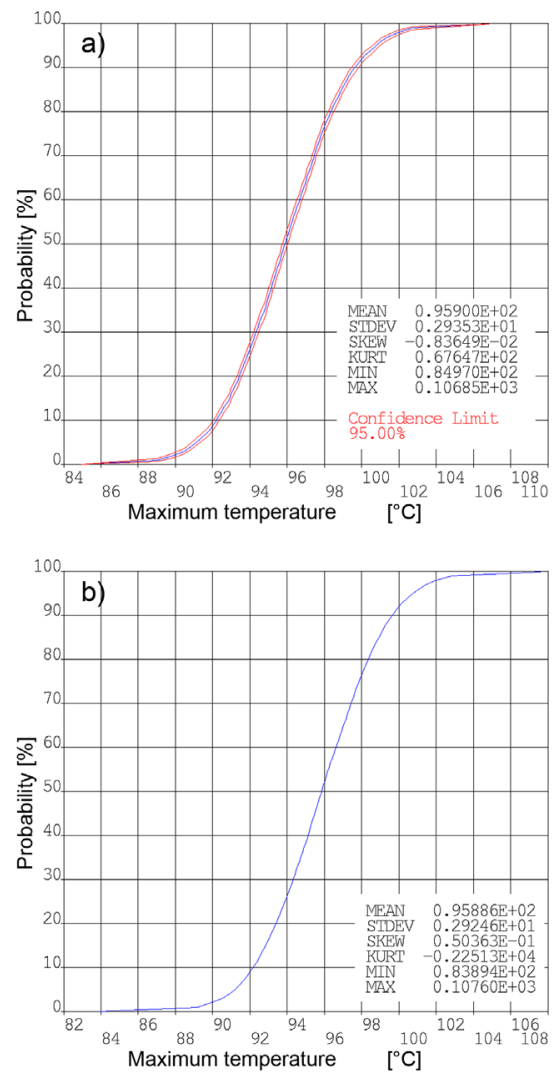

Fig. 8. Cumulative distribution function of maximum temperature; a) MCS, and b) RSM

The sensitivity of maximum temperature to random input variables for MCS and RSM is shown in Fig. 9. It can be seen that the radius of magnetic ring, applied voltage and thermal conductivity of 440C stainless steel have significant effects on the maximum temperature of subsea solenoid valve. The three variables are responsible for almost three quarters of the effect on the failure probability, with the other six variables together making up for the remaining one quarter. Therefore, more attention should be paid to the three variables when the valve is designed. The three variables are followed by thermal conductivity of $316 \mathrm{~L}$ stainless steel, thermal conductivity of conduction oil, outside the radius of plunger sleeve, inside the radius of plunger sleeve, the radius of the plunger and convection heat transfer coefficient of seawater for MCS $\left(R_{\mathrm{mr}}>U>k_{440}>\right.$ $k_{\mathrm{oil}}>k_{316}>R_{\mathrm{pso}}>R_{\mathrm{psi}}>R_{\mathrm{pl}}>h_{\mathrm{sea}}$ ), whereas they are followed by thermal conductivity of $316 \mathrm{~L}$ stainless steel, thermal conductivity of conduction oil, outside the radius of the plunger sleeve, convection heat transfer coefficient of seawater, inside the radius of the plunger sleeve and the radius of the plunger and for $\operatorname{RSM}\left(R_{\mathrm{mr}}>U>k_{440}>k_{\mathrm{oil}}>k_{316}>R_{\mathrm{pso}}>h_{\text {sea }}>\right.$ $\left.R_{\mathrm{psi}}>R_{\mathrm{pl}}\right)$. Although the orders of sensitivity for some random input variables are different, they have no significant influence on the maximum temperature, which can be ignored.
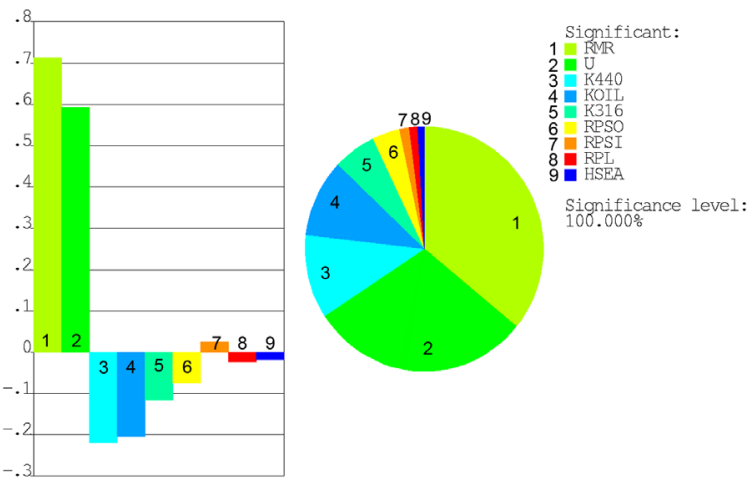

a)
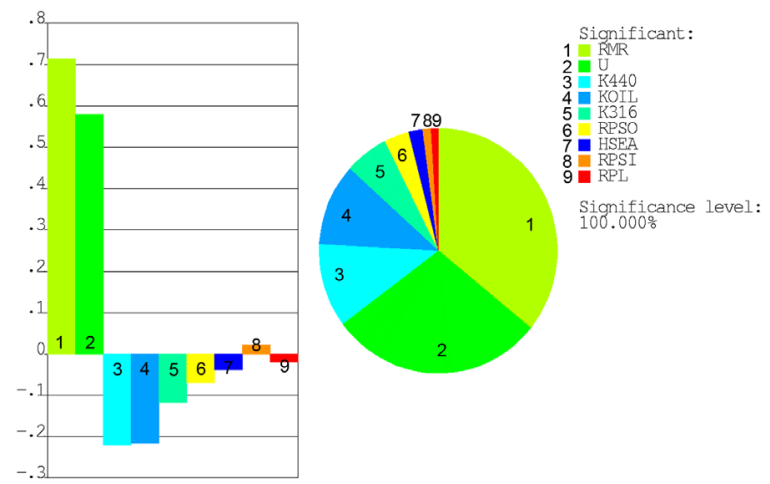

b)

Fig. 9. Sensitivity of maximum temperature to random input variables; a) MCS, and b) RSM

\subsection{Probabilistic Electromagnetic Analysis Results}

The mean electromagnetic forces for MCS and RSM are 143.53 and $148.17 \mathrm{~N}$, respectively, which are lower than the deterministic analysis results of 154.28 N. For the probabilistic electromagnetic analysis, only the sensitivity of electromagnetic force with the air gap of $0.25 \mathrm{~mm}$ to random input variables is given as shown in Fig. 10. It can be seen that the 
radius of plunger and inside radius of plunger sleeve have significant effects on the electromagnetic force of subsea solenoid valve. The two variables are responsible for three quarters or more of the effect on failure probability, with the other four variables together making up for the remaining part. Therefore, more attention should be paid to the radius of the plunger and inside radius of plunger sleeve when the valve is designed. The two variables are followed by applied voltage, the radius of magnetic ring, relative permeability of $440 \mathrm{C}$ stainless steel and outside radius of plunger sleeve $\left(R_{\mathrm{pl}}>R_{\mathrm{psi}}>U>R_{\mathrm{mr}}>\mu_{440}>R_{\mathrm{pso}}\right)$, whereas they are followed by radius of magnetic ring, applied voltage, outside radius of plunger sleeve and relative permeability of $440 \mathrm{C}$ stainless steel $\left(R_{\mathrm{pl}}\right.$ $\left.>R_{\mathrm{psi}}>R_{\mathrm{mr}}>U>R_{\mathrm{pso}}>\mu_{440}\right)$. Similarly, the orders of sensitivity for some unimportant random input variables are different.
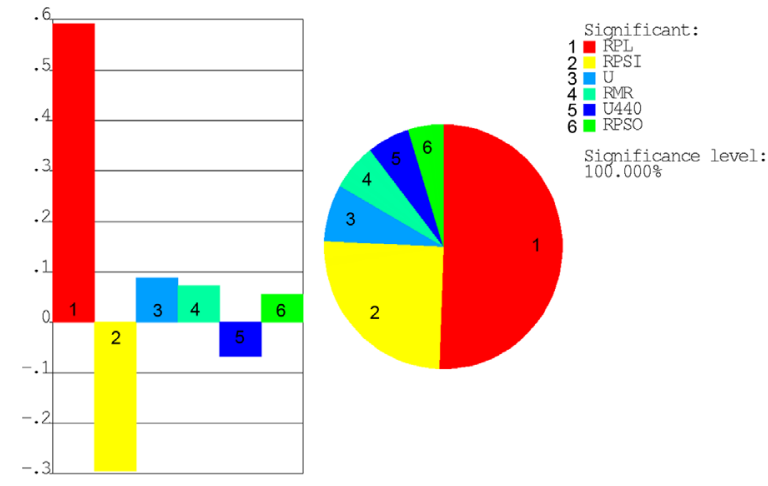

a)
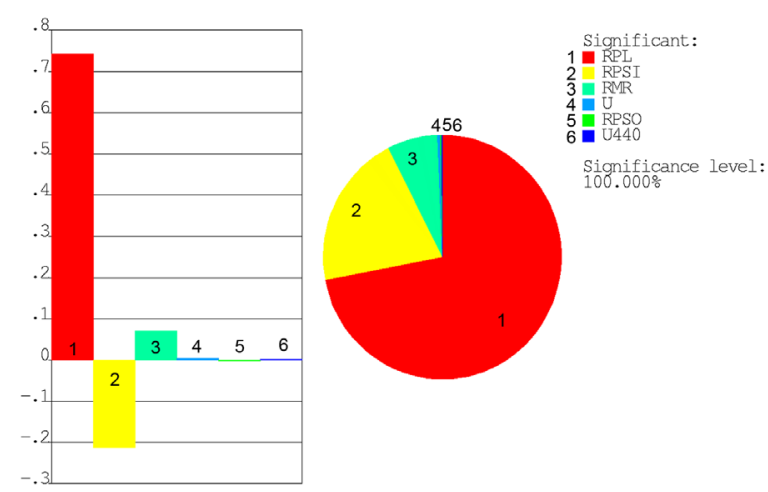

b)

Fig. 10. Sensitivity of electromagnetic force to random input variables; a) MCS, and b) RSM

\section{CONCLUSIONS}

The deterministic and probabilistic thermal and electromagnetic finite element analyses of subsea solenoid valves for subsea blowout preventers are performed by using ANSYS software. The effects of uncertainties of five material properties, four physical dimensions and an applied voltage on the maximum temperature within the valve and the electromagnetic force with a given air gap are researched. A prototype of subsea solenoid valve was manufactured, and the thermal and electromagnetic experiments were done to validate the finite element analysis results.

(1) The radius of the magnetic ring, applied voltage and thermal conductivity of $440 \mathrm{C}$ stainless steel have significant effects on the maximum temperature of subsea solenoid valve.

(2) The radius of the plunger and inside radius of the plunger sleeve have significant effects on the electromagnetic force of subsea solenoid valve.

(3) RSM and MCS predict different orders of sensitivity for some random input variables on maximum temperature and electromagnetic force; fortunately, they have small influences.

(4) The results of the finite element analysis and thermal and electromagnetic experiments indicate good matches.

(5) The probabilistic finite element analysis method shows the advantages in accelerating the development process and improving the performance of subsea solenoid valves.

\section{ACKNOWLEDGEMENTS}

The authors wish to acknowledge the financial support of the National High-Technology Research and Development Program of China (No. 2007AA09A101), National Natural Science Foundation of China (No. 50874115), Program for Changjiang Scholars and Innovative Research Team in University (IRT1086), Taishan Scholar project of Shandong Province (TS20110823), Shandong Province Science and Technology Development Project (2011GHY11520) and Incubation Programme of Excellent Doctoral Dissertation of China University of Petroleum (No. 2010-02).

\section{REFERENCES}

[1] Shaughnessy, J.M., Armagost, W.K. (1999). Problems of ultra-deepwater drilling. Proceedings of the IADC/ SPE Asia Pacific Drilling Technology Conference, APDT, Amsterdam, p. 179--188.

[2] Cai, B., Liu, Y., Tian, X., Wang, Z., Wang, F., Li, H., Ji, R. (2011). Optimization of submersible solenoid valves for subsea blowout preventers. IEEE Transactions on Magnetics, vol. 47, no. 2, p. 451-458, DOI:10.1109/ TMAG.2010.2100825. 
[3] Tao, G., Chen, H.Y., J, Y.Y., He, Z.B. (2002). Optimal design of the magnetic field of a high-speed response solenoid valve. Journal of Materials Processing Technology, vol. 129, no. 1-3, p. 555-558, DOI:10.1016/ S0924-0136(02)00633-7.

[4] Moses, A., Al-Naemi, F., Hall, J. (2003). Designing and prototyping for production. Practical applications of electromagnetic modeling. Journal of Magnetism and Magnetic Materials, vol. 254-255, p. 228-233, DOI:10.1016/S0304-8853(02)00963-0.

[5] Yatchev, I., Gueorgiev, V., Hinov, K. (2009). Optimization of an axisymmetric linear electromagnetic valve actuator. COMPEL: The International Journal for Computation and Mathematics in Electrical and Electronic Engineering, vol. 28, no. 5, p. 1249-1256, DOI:10.1108/03321640910969494.

[6] Yang, S.M., Huang, C.L. (2009). Design of a new electromagnetic actuator which can produce threedimensional forces. IEEE Transactions on Magnetics, vol. 45, no. 10, p. 4153-4156, DOI:10.1109/ TMAG.2009.2022951.

[7] Angadi, S.V., Jackson, R.L., Choe, S.Y., Flowers, G.T., Suhling, J.C., Chang, Y.K., Ham, J.K. (2009). Reliability and life study of hydraulic solenoid valve. Part 1 A multi-physics finite element model. Engineering Failure Analysis, vol. 16, no. 3, p. 874887, DOI:10.1016/j.engfailanal.2008.08.011.

[8] Wu, D., Xie, X., Zhou, S. (2010). Design of a normal stress electromagnetic fast linear actuator. IEEE Transactions on Magnetics, vol. 46, no. 4, p. 10071014, DOI:10.1109/TMAG.2009.2036606.

[9] Li, W.H., Du, H., Guo, N.Q. (2003). Finite element analysis and simulation evaluation of a magnetorheological valve. International Journal of Advanced Manufacturing Technology, vol. 21, vol. 6, p. 438-445.

[10] Salloom, M.Y., Samad, Z. (2011). Finite element modeling and simulation of proposed design magnetorheological valve. International Journal of Advanced Manufacturing Technology, vol. 54, no. 5-8, p. 421429, DOI:10.1007/s00170-010-2963-1.

[11] Reh, S., Beley, J.D., Mukherjee, S., Khor, E.H. (2006). Probabilistic finite element analysis using ANSYS. Structural Safety, vol. 28, no. 1-4, p. 17-43, DOI:10.1016/j.strusafe.2005.03.010.

[12] Liu, D., Lai, X., Ni, J., Peng, L., Lan, S., Lin, Z. (2007). Robust design of assembly parameters on membrane electrode assembly pressure distribution. Journal of Power Sources, vol. 172, no. 2, p. 760-767, DOI:10.1016/j.jpowsour.2007.05.066.

[13] Nakamura, T., Fujii, K. (2006). Probabilistic transient thermal analysis of an atmospheric reentry vehicle structure. Aerospace Science and Technology, vol. 10, no. 4, p. 346-354, DOI:10.1016/j.ast.2006.02.002.

[14]Zulkifli, M.N., Famal, Z.A.Z., Quadir, G.A. (2011). Temperature cycling analysis for ball grid array package using finite element analysis. Microelectronics International, vol. 28, no. 4, p. 1728, DOI: $10.1108 / 13565361111097083$.

[15] Nemeth, N.N., Evans, L.J., Jadaan, O.M., Sharpe, W.N., Beheim, G.M., Trapp, M.A. (2007). Fabrication and probabilistic fracture strength prediction of high-aspect-ratio single crystal silicon carbide microspecimens with stress concentration. Thin Solid Films, vol. 515, no. 6, p. 3283-3290, DOI:10.1016/j. tsf.2006.01.041.

[16] Liu, P.F., Zheng, J.Y. (2010). Strength reliability analysis of aluminium-carbon fiber/epoxy composite laminates. Journal of Loss Prevention in the Process Industries, vol. 23, no. 3, p. 421-427, DOI:10.1016/j. jlp.2010.02.002.

[17] Cai, B., Liu, Y., Li, H., Liu, Z. (2011). Buckling analysis of composite long cylinders using probabilistic finite element method. Mechanika, vol. 17 , no. 5, p. 467-473, DOI:10.5755/j01. mech.17.5.721.

[18] Cai, B., Liu, Y., Liu, Z. Tian, X. Ji, R., Zhang, Y. (2012). Probabilistic analysis of composite pressure vessel for subsea blowout preventers. Engineering Failure Analysis, vol. 19, p. 97-108, DOI:10.1016/j. engfailanal.2011.09.009.

[19] Chung, M., Gweon, D. (2003). Optimal design and development of electromagnetic linear actuator for mass flow controller. KSME International Journal, vol. 17 , no. 1, p. $40-47$

[20] Tsai, N., Chiang, C. (2010). Design and analysis of magnetically-drive actuator applied for linear compressor. Mechatronics, vol. 20, no. 5, p. 596-603, DOI:10.1016/j.mechatronics.2010.06.001.

[21] Cai, B., Liu, Y., Tian, X., Wang, F., Li, H., Ji, R. (2010). An experimental study of crevice corrosion behaviour of $316 \mathrm{~L}$ stainless steel in artificial seawater. Corrosion Science, vol. 52, no. 10, p. 3235-3242, DOI:10.1016/j.corsci.2010.05.040.

[22] Tanaka, S., Ueda, K., Mitamura, N., Oohori, M. (2006). The development of an austenitic stainless steel bearing with high corrosion resistance. Journal of ASTM International, vol. 3, no. 9, JAI100424, DOI:10.1520/JAI100424.

[23] Zheng, L., Neville, A., Gledhill, A., Johnston, D. (2009). An experimental study of the corrosion behavior of nickel tungsten carbide in some waterglycol hydraulic fluids for subsea applications. Journal of Materials Engineering and Performance, vol. 19, no. 1, p. 90-98, DOI:10.1007/s11665-0099416-8.

[24] Lipus, L. C., Acko, B., Hamler, A. (2012). Magnetic device simulation modelling and optimisation for scale control. International Journal of Simulation Modelling, vol. 11, no. 3, p. 141-149, DOI:10.2507/ IJSIMM11(3)3.205. 